\title{
Grade-related Liver injury management and its outcome
}

\author{
Amr Samak ${ }^{1}$ MSc;Hisham Abdeldayem²MD ; Maher Osman² MD; Mohammad Taha² MD
}

*Corresponding Author:

Amr Salem Samak

amrsamak@hotmail.com

Received for publication June 24, 2020; Accepted November 1, 2020; Published

onlineNovember 2, 2020.

Copyright 2020 The Authors published by Al-Azhar University, Faculty of Medicine, Cairo, Egypt. All rights reserved. This an open-access article distributed under the legal terms, where it is permissible to download and share the work provided it is properly cited. The work cannot be changed in anyway or used commercially.

doi:10.21608/aimj.2020.33761.1262

${ }^{1}$ General Surgery Department, ShebinElkom Teaching Hospital.

${ }^{2}$ Hepatobiliary and Pancreatic Surgery Department, National Liver Institute, MenoufiaUniversiry.

\section{INTRODUCTION}

Liver is more prone to injury due to large size, fixed position and thin capsule. It takes second place among all the injuries and achieve between 15$20 \%{ }^{1,2}$

Liver trauma varies between countries due to social, regulatory and environmental conditions. Blunt injuries are more popular in Europe while penetrating injuries have higher rates in USA. ${ }^{3}$

Until 1990, explorative laparotomy was used in liver trauma. The application of conservative management started with the introduction of CT for diagnosing abdominal trauma. ${ }^{4}$ Hemodynamic stability is the main determinant of the way of treatment of liver injury, although a higher grade injury is associated with higher incidence of laparotomy. ${ }^{5}$
Mortality due to liver injury is often determined by factors as grade and nature of injuries, associated injury, experiences of the treating institution and the medical history of the patients' themselves. ${ }^{3}$

The aim is to manage the patients with liver trauma according to grade of trauma and assess the outcome.

\section{PATIENT AND MATERIALS}

From January 2013 to January 2014, liver trauma patients presented to emergency departments of ShebinElkom Teaching hospital and National Liver Institute were enrolled. After initial evaluation and resuscitation with anti-shock measures and blood sampling for cross matching, a complete history was taken from every patient then a general examination was done to exclude associated injuries and an abdominal examination was done for presence of 
bruises, the site and depth of penetrating injuries and to detect acute abdomen.

Emergency laboratory investigations were drawn. Ultrasonography was done in all patients to detect hemoperitonium while the hemodynamic stable patients had CT scan to determine site and depth of injury, grading of liver trauma according to AAST Liver Injury Scale (Figure 1).

Two groups were then elicited; Stable and Unstable Groups. In the former group, conservative management was taken out. The inclusion criteria of the patients were stable hemodynamic status, good response to resuscitation, low blood transfusion requirements and absence of signs of peritonitis. ${ }^{6}$

The Conservative measures were ICU admission, absolute bed rest, pulse, blood pressure, respiratory rate and temperature charting and hemodynamic monitoring (serial hemoglobin, hematocrit value and prothrombin concentration). ${ }^{6}$ Continuous monitoring via serial examinations, serial follow up FAST and Abdominal CT were taken out to detect any changes. The criteria for discontinuing conservative management were the tachycardia and/or hypotension in the first 48 hours of observation, increased transfusion requirement, increased abdominal pain and tenderness, expansion of a hematoma on CT or a development of a symptomatic perihepatic fluid collection, hematoma or biloma. ${ }^{7}$

Operative intervention occurred in the other group. The criteria for immediate operation were hemodynamically instability on admission, recurrence of instability after stabilization, signs of peritonitis on physical examination and penetrating injuries in unstable patients. ${ }^{7}$

Intraoperatively, compression and perihepatic packing was done then injury was assessed. If there was superficial capsular tear or laceration, gel foam was used. If the injury was superficial, suture hepatorraphy was done (Figure 2). Deep or avulsed injuries were resected. In massive uncontrollable bleeding and/or hemodynamic instability, perihepatic packing was done with reexploration after proper resuscitation. Hemostasis was done either by omental pack, Gelfoam or cauterization. Drains were inserted in the hepatorenal pouch and the pelvis and the wound was closed.

Postoperatively, closed monitoring occurred in ICU then they either stay or transferred to surgical ward. Postoperative follow-up include close monitoring of pulse, blood pressure, respiratory rate, temperature and drains and full laboratory investigations every other day. If there was more than $100 \mathrm{cc} / \mathrm{hr}$ blood collection, the abdomen was reexplored. In all patients, morbidity, mortality and length of hospital stay were recorded. Follow-up data were recorded.

Data were collected and tabulated for statistical analysis by Statistical Package for Social Science (SPSS) program version 26, Chicago, Illinois, USA. Descriptive statistics was expressed as mean, SD, range and Chi-square test in quantitative data and as percentage, frequency and Student t-test in qualitative analysis. Kaplan-Meier survival analysis and multiple logistic regression analysis were used for multivariate analysis. $\mathrm{P}$ value was considered significant if it was less than 0.05 .

\section{RESULTS}

Thirty patients were assigned into 2 groups according to their hemodynamic status after resuscitation; stable group including 18 patients and unstable group including 12 patients. Demographically, no statistical significance difference was found. Among the stable group, one patient was diabetic while the other was hypertensive. In the unstable group, only one patient (3.33\%) was diabetic. Blunt trauma occurred in 24 patients mainly road traffic accident. Stab abdomen was found to be the main cause of penetrating trauma. No significance was found between both groups in regards the interval that passed from trauma to admission (Table 1 ).

The mean value of hematocrit was higher in stable group (p 0.003). The total leucocytic count, ALT and AST were higher in the unstable group (p 0.014, $0.007,0.008$ respectively). No significance was found in regards to the amount of free fluid detected by ultrasonography. Eleven patients in the stable group were found to have no co-injuries while one patient only in the unstable group was found to have no co-injury (p 0.004) (Table 2).

In the stable group, 2 patients developed hemodynamic instability and/or peritonitis during the first 48 hours and they were transferred to OR (p $0.001)$. In the unstable group, 6 patients required suture hepatorraphy while 2 patients had damage control therapy. In the stable group, 14 patients did not need any further management while 2 patients had medical treatment for brain oedema, one patient had chest tube insertion for hemopneumothorax and another one had skin traction for fracture femur. In the unstable group, one patient did not need any further management while 4 patients had splenectomy, 3 patients had chest tube insertion, 2 patients had intraoperative reduction of eviscerated viscus. One patient had a repair of enterotomy (Table $3)$.

After the management, Grade II was the most in the stable group while it was grade III and IV in the other group ( $p$ 0.0023). There were high requirements of blood transfusion in the unstable group (p 0.003). 3 patients stayed in ICU for further observation in stable group because of severity of trauma or severe co-injuries while 7 patients in the other group required postoperative ICU (p 0.018) (Table 4).

In stable group, fifteen patients had no morbidity. Two patients had hemorrhage with failure of conservative treatment and reexploration occurred after 48 hours. No mortality was encountered in the 
stable group. In the other group, massive hemorrhage was observed through the drains in 3 patients; one of them responded to correction of coagulopathy while the other 2 cases died postoperatively from severe irreversible shock and DIC. 3 patients suffered from biliary leakage; one case responded to medical treatment, one case underwent ultrasound guided aspiration and one case underwent ERCP and stenting. One patient had seroma in which antibiotics and repeated dressing were successful (Table 5).

The most important risk factors that can affect the management were the grade of injury (p 0.002, OR
2.92). The survival probability after 16 hours from admission was $93.3 \%$ in all patients, $83.3 \%$ in the unstable and $100 \%$ in the stable group (Figure 3).

On follow-up, 15 patients in stable group showed satisfactory progress while one patient had subphrenic abscess that resolved by antibiotics, one patient had subhepatic collection that resolved by sonar guided aspiration. One patient with hepatitis required hepatology consultation. In the unstable group, six patients were free while 2 patients had subphrenic abscess and 2 patients had secondary sutures for gapped wound (Figure 4).

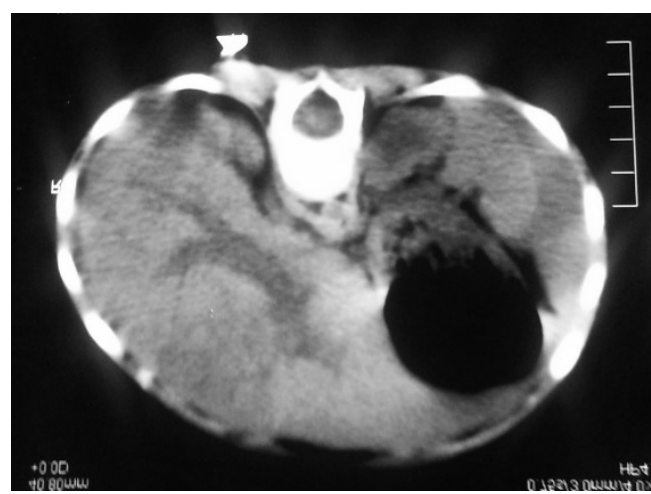

Figure 1: CT shows intraparenchymal hematoma (Grade III hepatic injury) in a female patient, 2 years old with history of RTA who responded to conservative management.
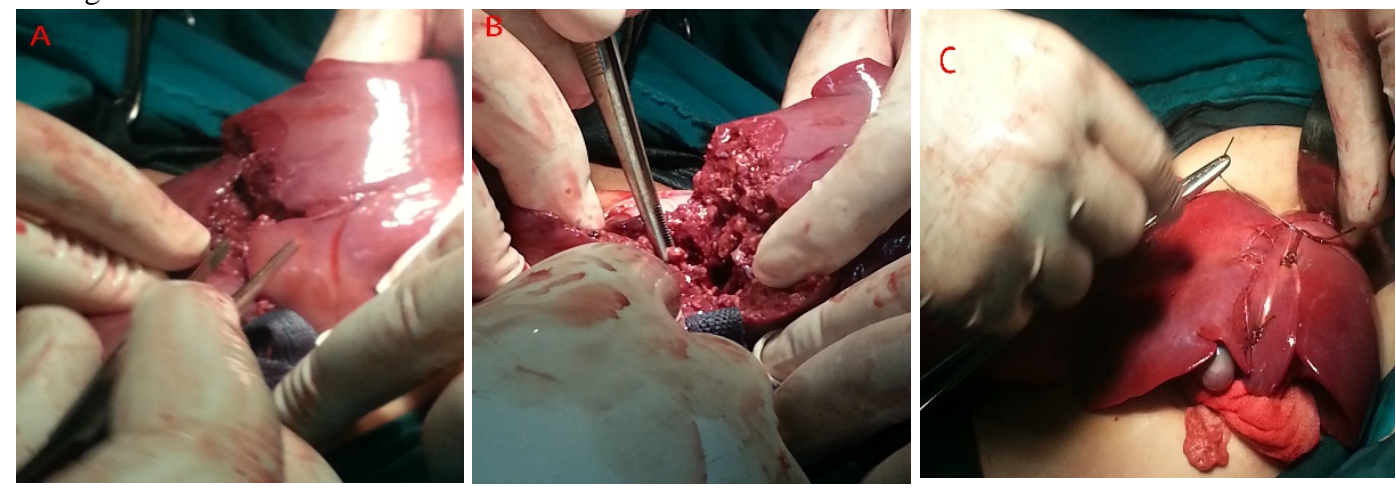

Figure 2 Exploration reveals an extensive tear (Grade III) in segment IV to the left of the gall bladder (A, B). Suture hepatorraphy was done together with gel foam (C). 
Survival Plot for Time in hours op

Kaplan-Meier Method

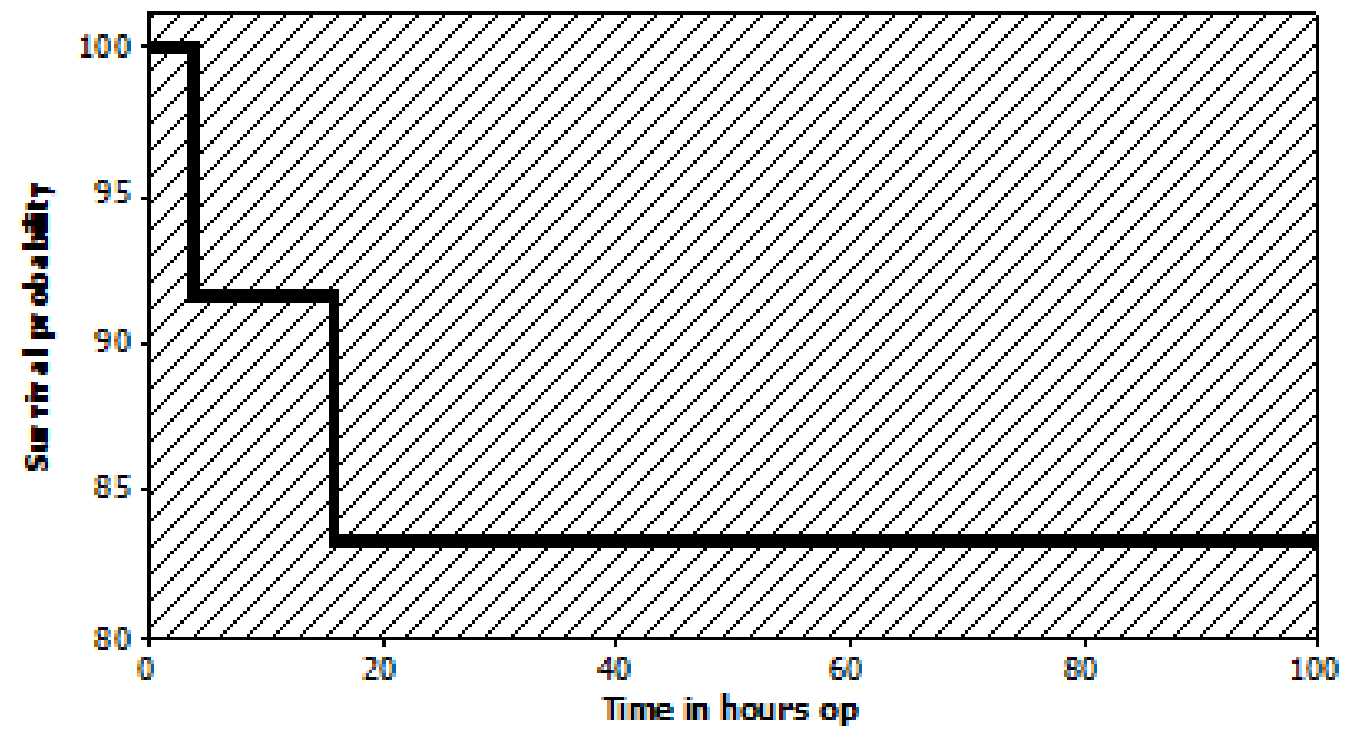

Figure 3 Results of Kaplan-Meier survival analysis test.

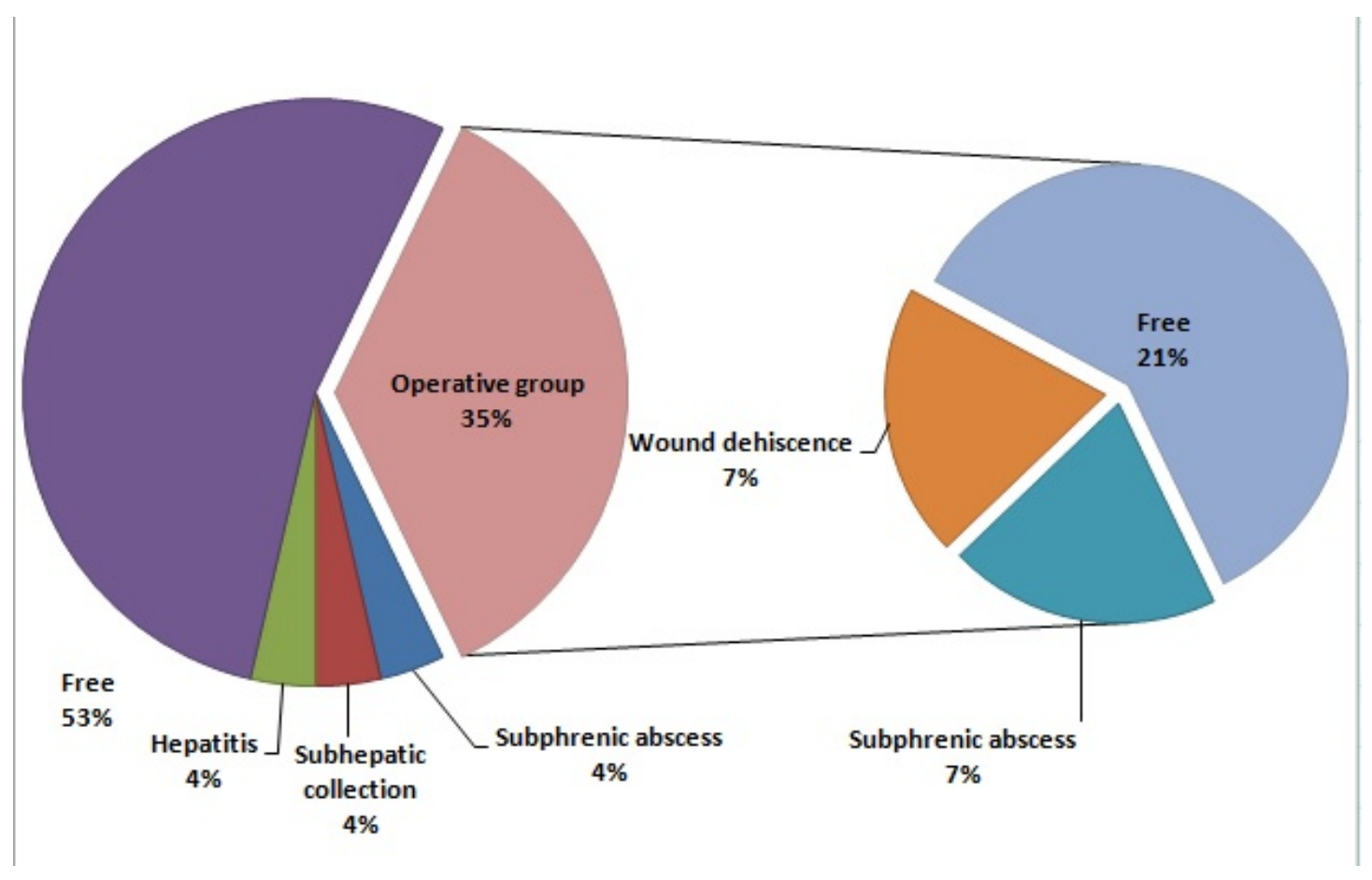

Figure 4 Follow-up among the conservative group. 


\begin{tabular}{|c|c|c|c|c|c|c|c|c|}
\hline & & \multicolumn{3}{|c|}{ Stable } & \multicolumn{3}{|c|}{ Unstable } & p value \\
\hline \multirow{2}{*}{ Sex } & Male & \multicolumn{3}{|c|}{14} & \multicolumn{3}{|c|}{10} & \multirow[t]{2}{*}{0.709} \\
\hline & Female & \multicolumn{3}{|c|}{4} & \multicolumn{3}{|c|}{2} & \\
\hline \multirow[t]{8}{*}{ Age } & \multirow{4}{*}{$\begin{array}{l}\text { Pediatric } \\
<18 \text { years }\end{array}$} & \multicolumn{2}{|r|}{ No. } & 6 & \multicolumn{3}{|c|}{4} & \\
\hline & & \multicolumn{2}{|c|}{ Mean } & 12 & \multicolumn{3}{|c|}{8} & \multirow[t]{3}{*}{0.235} \\
\hline & & \multicolumn{2}{|r|}{ SD } & 5.1 & \multicolumn{3}{|c|}{4.6} & \\
\hline & & \multicolumn{2}{|c|}{ Range } & 13 & \multicolumn{3}{|c|}{11} & \\
\hline & \multirow{4}{*}{$\begin{array}{c}\text { Adult } \\
>18 \text { years }\end{array}$} & \multicolumn{2}{|r|}{ No. } & 12 & \multicolumn{3}{|c|}{8} & \\
\hline & & \multicolumn{2}{|c|}{ Mean } & 28.7 & \multicolumn{3}{|c|}{25.8} & \multirow[t]{3}{*}{0.398} \\
\hline & & \multicolumn{2}{|r|}{ SD } & 10.1 & \multicolumn{3}{|c|}{4.7} & \\
\hline & & \multicolumn{2}{|c|}{ Range } & 35 & \multicolumn{3}{|c|}{14} & \\
\hline \multirow[t]{3}{*}{ Weight } & $<50 \mathrm{~kg}$ & 4 & Mean & 63.39 & 4 & Mean & 59.42 & \multirow[t]{3}{*}{0.693} \\
\hline & $51-100 \mathrm{~kg}$ & 13 & SD & 21.51 & 7 & SD & 29.4 & \\
\hline & $>100 \mathrm{~kg}$ & 1 & Range & 83 & 1 & Range & 90 & \\
\hline \multirow{2}{*}{$\begin{array}{c}\mathrm{Co}- \\
\text { morbidities }\end{array}$} & Present & \multicolumn{3}{|c|}{2} & \multicolumn{3}{|c|}{1} & 0.804 \\
\hline & Absent & & 16 & & & 11 & & \\
\hline Mechanism & Blunt & & 16 & & & 8 & & 0.136 \\
\hline of trauma & Penetrating & & 2 & & & 4 & & \\
\hline Interval fr & trauma to & & lean & 3.58 & & 4.83 & & 0.399 \\
\hline adn & ion & & SD & 3.7 & & 4 & & \\
\hline & & & ange & 11.5 & & 14 & & \\
\hline
\end{tabular}

Table 1 The demographic data among patients included in the study.

\begin{tabular}{|c|c|c|c|c|}
\hline & & Stable & unstable & p value \\
\hline \multirow{3}{*}{$\begin{array}{l}\text { Hemoglobin } \\
\text { (g/dl) }\end{array}$} & Mean & 8.38 & 7.55 & \multirow[t]{3}{*}{0.221} \\
\hline & $\mathrm{SD}$ & 0.947 & 1.531 & \\
\hline & Range & 2.2 & 5 & \\
\hline \multirow{3}{*}{$\begin{array}{l}\text { Hematocrit } \\
(\%)\end{array}$} & Mean & 32.44 & 24.92 & \multirow[t]{3}{*}{0.003} \\
\hline & $\mathrm{SD}$ & 5.98 & 5.95 & \\
\hline & Range & 22 & 19 & \\
\hline \multirow{3}{*}{$\begin{array}{l}\text { Total leucocytic } \\
\text { count (cell/ } \boldsymbol{\mu L})\end{array}$} & Mean & 7156 & 11533 & \multirow[t]{3}{*}{0.014} \\
\hline & $\mathrm{SD}$ & 2012 & 5097 & \\
\hline & Range & 7800 & 19900 & \\
\hline \multirow{3}{*}{$\begin{array}{c}\text { Alanine amino- } \\
\text { transferase } \\
\text { (ALT) }\end{array}$} & Mean & 395.8 & 625.1 & \multirow[t]{3}{*}{0.007} \\
\hline & $\mathrm{SD}$ & 200 & 210.4 & \\
\hline & Range & 665 & 649 & \\
\hline \multirow{3}{*}{$\begin{array}{l}\text { Aspartate } \\
\text { amino- } \\
\text { transferase } \\
\text { (AST) }\end{array}$} & Mean & 253.3 & 446 & \multirow[t]{3}{*}{0.008} \\
\hline & SD & 137.3 & 195 & \\
\hline & Range & 446 & 634 & \\
\hline \multirow{5}{*}{$\begin{array}{c}\text { Focused } \\
\text { Assessment with } \\
\text { Sonography for } \\
\text { trauma } \\
\text { (FAST) }\end{array}$} & No collection & 2 & 0 & \multirow[t]{5}{*}{0.14} \\
\hline & Minimal & 5 & 2 & \\
\hline & Mild & 6 & 1 & \\
\hline & Moderate & 5 & 7 & \\
\hline & Marked & 0 & 2 & \\
\hline \multirow{2}{*}{$\begin{array}{l}\text { Presence of co- } \\
\text { injuries }\end{array}$} & Present & 7 & 11 & \multirow[t]{2}{*}{0.004} \\
\hline & Absent & 11 & 1 & \\
\hline
\end{tabular}

Table 2 The clinical findings among patients included in the study. 


\begin{tabular}{|c|c|c|c|c|}
\hline & & Stable & unstable & p value \\
\hline \multirow{2}{*}{$\begin{array}{l}\text { Conservative } \\
\text { Management }\end{array}$} & Successful & 16 & - & \multirow[t]{2}{*}{0.001} \\
\hline & $\begin{array}{l}\text { Conversion to } \\
\text { OR }\end{array}$ & 2 & - & \\
\hline \multirow{4}{*}{$\begin{array}{c}\text { Operative } \\
\text { Management }\end{array}$} & Compression & 1 & 2 & \multirow[t]{4}{*}{0.6694} \\
\hline & $\begin{array}{c}\text { Suture } \\
\text { hepatorraphy }\end{array}$ & 1 & 6 & \\
\hline & Resection & - & 2 & \\
\hline & Damage control & - & 2 & \\
\hline \multirow{2}{*}{$\begin{array}{c}\text { The need for further } \\
\text { management }\end{array}$} & Required & 4 & 11 & \multirow[t]{2}{*}{0.001} \\
\hline & Not required & 14 & 1 & \\
\hline
\end{tabular}

Table 3: The Management of the patients included in the study.

\begin{tabular}{|c|c|c|c|c|}
\hline & & Stable & Unstable & p value \\
\hline \multirow{5}{*}{$\begin{array}{l}\text { Trauma Grade } \\
\text { (AAST) }\end{array}$} & Grade I & 6 & 2 & \multirow[t]{5}{*}{0.0023} \\
\hline & Grade II & 9 & 0 & \\
\hline & Grade III & 3 & 4 & \\
\hline & Grade IV & 0 & 4 & \\
\hline & Grade V & 0 & 2 & \\
\hline \multirow{2}{*}{$\begin{array}{l}\text { Requirements for } \\
\text { blood transfusion }\end{array}$} & Required & 5 & 10 & \multirow[t]{2}{*}{0.003} \\
\hline & $\begin{array}{c}\text { Not } \\
\text { required }\end{array}$ & 13 & 2 & \\
\hline \multirow{3}{*}{$\begin{array}{c}\text { Average amount } \\
\text { of transfused } \\
\text { packed RBCs }\end{array}$} & Mean & 4.4 & 4.7 & \multirow[t]{3}{*}{0.746} \\
\hline & SD & 1.14 & 2.359 & \\
\hline & Range & 3 & 8 & \\
\hline \multirow[t]{3}{*}{ The site of injury } & Right lobe & 12 & 7 & \multirow[t]{3}{*}{0.889} \\
\hline & Left lobe & 5 & 4 & \\
\hline & Both lobes & 1 & 1 & \\
\hline \multirow[t]{2}{*}{ ICU admission } & Yes & 3 & 7 & \multirow[t]{2}{*}{0.018} \\
\hline & $\mathrm{NO}$ & 15 & 5 & \\
\hline \multirow{3}{*}{$\begin{array}{c}\text { Length of Hospital } \\
\text { stay } \\
\text { (in days) }\end{array}$} & Mean & 7.72 & 11.25 & \multirow[t]{3}{*}{0.170} \\
\hline & SD & 4.81 & 7.53 & \\
\hline & Range & 15 & 29 & \\
\hline
\end{tabular}

Table 4: The outcome findings among the patients included in the study.

\begin{tabular}{|c|c|c|c|c|}
\hline & & Stable & Unstable & p value \\
\hline \multirow[t]{2}{*}{ Morbidity } & Present & 3 & 7 & \multirow{2}{*}{0.018} \\
\hline & Free & 15 & 5 & \\
\hline \multirow[t]{2}{*}{ Mortality } & Deaths & 0 & 2 & \multirow[t]{2}{*}{0.073} \\
\hline & Alive & 18 & 10 & \\
\hline \multirow{2}{*}{$\begin{array}{l}\text { Follow up after } \\
\text { discharge }\end{array}$} & Diseased & 3 & 4 & \multirow[t]{2}{*}{0.172} \\
\hline & Free & 15 & 6 & \\
\hline
\end{tabular}

Table 5: Morbidity and mortality among the patients included in the study. 


\section{DISCUSSION}

Non surgical treatment of liver injuries in patients with hemodynamic stability was reported to be safe and efficient in the beginning of 1990's. ${ }^{7}$ In this study, 18 patients $(60 \%)$ were treated conservatively with only 2 patients (11.11\%) had failed the conservation. This is lower than Asfar and colleagues study where 98 patients (83\%) treated conservatively with 4 patients $(4.08 \%)$ failed. ${ }^{8}$

The unstable group formed of 12 patients (40\%) with death in 2 patients $(16.67 \%)$ which matches the study performed by Bernardo and colleagues in which the unstable group formed about 56 patients (39.2\%) with death in 16 patients (28.57\%) and the study performed by Sreeramulu and others in which the unstable group formed about 24 patients (43.6\%) with death in 5 patients (20.8\%). ${ }^{9,6}$

Demographically, it is usual that male young adults are more susceptible to trauma as they are normally more involved in many hazardous activities so it is not surprisingly that male in this study represents $80 \%$ of the patients and the patients aged $21.8 \pm$ 10.98 years in the stable group and $19.83 \pm 9.8$ years in the unstable group. These results match the results of a study performed by Asfar and colleagues in which male to female ratio represents (4:1) and the mean age was $29.02 \pm 11.18$ years. ${ }^{8}$

A study held in China stated that the presence of chronic kidney disease and liver cirrhosis increase the mortality among liver trauma patients while diabetes and hypertension did not. In our study, comorbidities did not affect the method of management. The difference could be due to that there were no such severe diseases among patients included in this study. ${ }^{10}$

Road traffic accidents were the most common cause of trauma in this study (16 patients; 54\%) which match a study performed by Hamdy and colleagues in which victims of road traffic accident compromised $57 \%$ of the mechanism of injury. These results, in both studies performed in Egypt, point to the problem of motor vehicle accidents there.

In this study, 24 patients had blunt liver trauma with 16 patients of them treated conservatively. On contrary, 4 patients out of 6 penetrating trauma patients were treated operatively. In Hamdy and colleagues study, 32 patients out of 42 patients had blunt trauma while 6 out of 10 patients with penetrating trauma treated operatively. ${ }^{7}$ The high incidence of operative intervention in penetrating liver trauma may be due to more aggressive nature of the penetrating trauma.

All patients in this study had FAST scan. FAST scan revealed that 12 patients had moderate amount of intraperitoneal free fluid; 5 patients out of them had successful conservative management so the method of management cannot be determined by the amount of fluid detected by FAST scan.

In this study, the right lobe was most affected. This matches Sreeramulu study where the most common site of injury was also the right lobe. ${ }^{6}$ The prevalence of right lobe injury can be attributed to its large size and proximity to the ribs.

Suture hepatorraphy was used in 7 patients; 6 in the unstable group and one patient in the stable group after failure of the conservation. Resection was done for 2 patients (Both were grade IV); one patient had left hepatectomy while the other had non anatomical debridement and resection. Damage control therapy was done for 2 patients (Both were grade V); both died postoperatively from severe shock and DIC. Nothing was done in 2 patients where a subcapsular hematoma of grade I was found. In Hamdy and colleagues study, $40 \%$ of the unstable group underwent suture hepatorraphy compared to $50 \%$ of the unstable group in our study.

In our study, the difference in the mean hospital stays in both groups showed no significance that means that the method of management had no effect on hospital stay. We found also that the interval that passed from trauma to admission did not affect the outcome.

Follow-up was done by clinical examination and imaging. 21 patients showed satisfactory progress. Only 2 patients required surgical intervention to close a gapped wound by secondary sutures while the others got their management in the form of either intervention radiology or medical treatment.

In this study, the outcome was affected by the vital status of the patients at the time of admission and the effect of resuscitation afterwards, the requirement of blood transfusion, AAST grading, the presence of coinjuries, the need for further management, the need for ICU admission and the presence of morbidity.

Regarding the vital status, 4 patients in the stable group were admitted vitally unstable but they responded to the resuscitation measures afterwards and became stable while 5 patients in the unstable group were admitted vitally stable but they deteriorated within few hours and required to be transferred to OR. In Hamdy and colleagues study, 2 stable patients became unstable and 14 unstable patients became stable on resuscitation and observation. $^{7}$

15 patients in our study required blood transfusion. It is a bit different from Asfar study, in which, $70 \%$ of the patients (81 out of 117 patients) required blood transfusion but it is similar to Bernardo study where only 78 out of 143 patients required blood transfusion. ${ }^{8,9}$ 
By AAST classification, 9 patients were found to have grade II liver injury. All of them were treated conservatively. 6 patients in the unstable group were found to have complex liver injury (grade IV, V and VI); no one of them could be treated conservatively as most of them presented in shock, sustained multiple associated injuries and significant blood losses making them more liable to operative management.

Also, complications were found among the patients with complex liver injury. In this study, 5 out of 10 patients who developed complications had complex liver injury. This was lower than Asensio and others study where $77 \%$ of patients who developed complications had either grade 4 or 5 liver injuries. So, operative management is a predictor of a high rate of complication. The combination of nonfavorable patient physiology, surgical hemostasis, and high-grade liver injury are also related to the higher number of complications. ${ }^{11}$

The presence of co-injuries and the need for further management also affected the outcome. 18 patients proved to have co-injury. 11 out of 12 patients in the unstable group were found to have a co-injury; 10 of them required surgical intervention to control the injury.

From all these factors that affected the outcome individually in our study, the AAST grading of the injury was the most important determinate of the method of management in liver trauma patients.

\section{CONCLUSION}

The AAST grade of injury can be a factor with the vital status in determining the appropriate method of management of liver trauma patients. The conservative management is more compatible with low grade injuries (Grade I, II and III) while the operative management is more compatible with high grade injuries (Grade IV, V and VI).

\section{REFERENCES}

1. Alexei L., Michael R. and Vladimir P.: Results of Surgical Treatment of Patients with Liver Laceration from Blunt Abdominal Trauma. International journal of biomedicine, 2012, 2, 3: 169-173.

2. Helling T., Ward M. and Balon J.: Is the grading of liver injuries a useful clinical tool in the initial management of blunt trauma patients? European Journal of trauma and emergency surgery, 2009, 35: 95-101.

3. Sivakumar G. and Beardsley C., An overview of liver trauma. MSJA, 2011, 3:1.

4. Van Vugt R., Bosscha K., Olsman J. et al., Management of Hepatic Trauma: a 9-Year
Experience in's-Hertogenbosch. ActaChirBelg, 2009, 109: 42-46.

5. Nasim A. and Jerome J., Management of liver trauma in adults. Journal of Emergencies, trauma and shock, 2011, 4(1):114-119.

6. Sreeramula P., Venkatachalapathy T. and Anantharaj, Blunt trauma liver-conservative or surgical management: A retrospective study. $J$ trauma treat, 2012, 1(8): 146.

7. Hamdy H., Nasr M., AbouEisha H. et al., Evaluation of management options for traumatic liver injuries. Egyptian Journal of Surgery (EJS), 2012, 31: 16-23.

8. Asfar S., Khoursheed M., Al-Saleh M. et al., Management of liver trauma in Kuwait. Med PrincPract., 2014, 23(2): 160-166.

9. Bernardo C., Fustera J., Bombuya E. et al., Treatment of Liver Trauma: Operative or Conservative Management. Gastroenterology research, 2010, 3: 9-18.

10. Chien L., Lo S. and Yeh S., Incidence of liver trauma and relative risk factors for mortality: a population-based study. J Chin Med Assoc., 2013, 76(10): 576-582.

11. Asensio J., Demetriades D., Chahwan S. et al., Approach to the management of complex hepatic injuries. Journal of trauma, 2000, 48: 66-70. 